\title{
Analysis of differentially expressed genes during embryogenesis in ovary culture of cucumber (Cucumis sativus L.)
}

\section{Ying Deng}

Nanjing Agricultural University;Institute of Horticulture, Guizhou Academy of Agricultural Sciences

\section{Wenyuan Fu}

Institute of Horticulture,Guizhou Academy of Agricultural Sciences

\section{Bing Tang}

Institute of Horticulture,Guizhou Academy of Agricultural Sciences

\section{Lian Tao}

Institute of Horticulture, Guizhou Academy of Agricultural Sciences

\section{Lu Zhang}

Nanjing Agricultural University

\section{Xia Zhou}

Nanjing Agricultural University

Ji LI

Nanjing Agriculture University

Jinfeng Chen ( $\nabla$ jfchen@njau.edu.cn )

Nanjing Agricultural University https://orcid.org/0000-0003-0127-3070

\section{Research article}

Keywords: Cucumber, Ovary culture, Embryogenesis, Transcriptome, Differentially expressed genes

Posted Date: June 13th, 2019

DOI: https://doi.org/10.21203/rs.2.10287/v1

License: (1) (1) This work is licensed under a Creative Commons Attribution 4.0 International License. Read Full License 


\section{Abstract}

Background: Ovary culture has been a useful way to generate double haploid $(\mathrm{DH})$ plant in cucumber (Cucumis sativus L.). However, the rate of embryo induction is low, and the probability for the induced embryo to grow into normal embryo is low as well. This is largely due to unknown of the mechanism of embryogenesis in cucumber. In this study, the differentially expressed genes during embryogenesis, including the early stages of embryo formation, embryo maturation and shoot formation, was investigated with transcriptomic technique to set up basis for a more efficient ovary culture technology Results: Cytological observations led to suggestions that cell enlargement is the symbol that gametophytes had switched to the sporophyte development pathway during the early embryogenesis stage. In this stage, RNA-seq revealed 3468 up-regulated genes, including hormone signal transduction genes, hormone response genes and stress-induced genes. The reported embryogenesis-related genes BBM, HSP90 and AGL were also actively expressed during this stage. The total of 480 genes that function in protein complex binding, microtubule binding, tetrapyrrole binding, tubulin binding and other microtubule activities were continuously up-regulated during the embryo maturation stage, indicating that the cytoskeleton structure was continuously being built and maintained by the action of microtubulebinding proteins and enzyme modification during embryo development. In the shoot formation stage, 1383 genes were up-regulated, which were mainly enriched in phenylpropanoid biosynthesis, plant hormone signal transduction, phenylalanine metabolism, and starch and sucrose metabolism. The shoot formation stage might be regulated by 6 transcription factors that contained a B3 domain, 9 genes in the AP2/ERF family and 2 genes encoded WUS homologous domain proteins. Conclusions: Findings from this study offer a valuable framework for explaining the transcriptional regulatory mechanism underlying embryogenesis in cucumber ovary culture.

\section{Background}

Gametophyte culture involved a stress-induced reprogramming of male or female gametophytes to develop into embryo-like structures, which can be directly regenerated into completely homozygous, doubled haploid (DH). The study of male gametophyte (microspore) embryogenesis began in the 1960s [1]. Microspore embryogenesis in vitro can be easily monitored and provides a convenient experimental platform for large-scale physiological and biochemical analyses [2]. However, the study of gynogenesis is not simple; the embryo sac is small and embedded in surrounding tissues, making early embryos difficult to observe and isolate. Despite these difficulties, to inducing gynogenesis in vitro, especially when the haploid induced by the male gametophyte is not successful or the induction rate is too low and when self-incompatibility, male-sterile and dioecious plants occurs, is an effective way to obtain haploid or double haploid plants [3]. In vitro gynogenesis is mainly used in the Cucurbitaceae, and previous studies have revealed that this technique is still imperfect and that the embryogenesis rate is low [4-11]. The study of the mechanism of embryogenesis has therefore been delayed, and the understanding of the mechanisms underlying gynogenesis induction is extremely limited. 
In general, embryogenesis is a stress-induced phenomenon. Micropores are cultured and develop into embryos in vitro, and stress treatments involving cold or heat shock and hormones are used as trigger factors to induce gametocytes to follow the sporophyte development pathway [12]. The genes associated with the reprogramming phase and the early stage of embryogenesis were slowly characterized, such as AGL 15-related proteins and the AGL 15 gene, the BBM gene and HSPgene [13-15]. More recently, the use of functional genomics tools has made it possible to identify more genes associated with different stages of microspore embryogenesis. In Brassica napus, the expression of embryogenesis-related genes such as $B B M, \angle E C 1$ and $\angle E C 2$ was detected after culture under heat stress at $32^{\circ} \mathrm{C}$ for three days; after incubation at $24{ }^{\circ} \mathrm{C}$, embryo-specific expressed genes, such as $L E C 1, \angle E C 2$ were detected [2]. The expression of genes associated with metabolism, chromosome remodeling, transcription, and translation signaling was up-regulated during the stress treatment stage in tobacco [16]. Similarly, genes related to metabolism, cell walls and the cell membrane, cell tissue control, cell communication and signal transduction were detected in the early stage of rape embryogenesis [17]. High levels of $B B M$ and $L E C$ gene expression have been confirmed in the early embryonic development of sweet pepper anther cultures [18]. The transition from microspores to developing embryos is mainly manifested in the induction of transcription factor genes that play an important role in early embryogenesis. Many genes are involved in hormone biosynthesis and plant hormone signal transduction and are involved in secondary metabolism [19]. Studies have shown that differentially expressed genes can be detected by gene chips in in vitro gynogenesis of cucumber in the early stage and have suggested that phenylalanine metabolism and phenylalanine synthesis may play an important role in the early development of cucumber in vitro [20].

Cucumber (Cucumis sativus L.) is the fourth most important vegetable worldwide [21]. Cucumber production in China ranks first worldwide. To date, the cultivated area of cucumber in China has reached 1.258 Mha [22]. Cucumber is thought to be one of the oldest vegetable crops and has been domesticated in China for probably 2000 years [23]. To meet the needs of production, breeders are constantly looking for valuable germplasm resources of valuable characteristics, especially resistance to disease and environmental stresses such as cold, drought, or salt stress [24]. To facilitate these breeding efforts, we can collect extensive germplasm resources for variety improvements. However, cucumber is a crosspollinated plant with obvious heterosis. Therefore, almost all the cucumber varieties in production are hybrids; however, the purification process of the hybrids is slow and long. In the breeding of parents, it takes 6-8 years of artificial self-breeding to develop a stable inbred line. To accelerate the purification of cucumber parents and improve breeding efficiency, haploid gametophyte cultures can be used to induce embryoids, and homozygous double haploids can be obtained in 1-2 years. DH technology is a powerful tool to speed up plant breeding. However, additional research is needed to improve our understanding of the genes or the roles of genes involved in embryogenesis and the mechanism of haploid induction in embryo sacs [25].

This study was based on the highly efficient in vitro ovary culture technology system of cucumber (unpublished). We divided the process from acquiring embryogenic potential to plant regeneration into 
three stages: early embryo development, embryo maturation (from pre-embryos to cotyledon embryos) and the shoot formation stage. We evaluated the embryo morphology and transcriptomes at different developmental stages during embryogenesis in cucumbers via ovary culture. The metabolism and biological process of embryogenesis in the gynogenesis of cucumber are discussed, and several key genes regulating embryogenesis were identified.

\section{Result}

\section{Morphological and cytological characterization of embryogenesis in cucumber}

The embryogenesis early stage, embryo maturation stage and shoot formation stage were observed to discern the cytological changes during embryogenesis by ovary culture in cucumber. Ovaries at $6 \mathrm{~h}$ before anthesis were collected and pretreated at $4{ }^{\circ} \mathrm{C}$. The ovaries were sterilized, sliced, inoculated into the medium, incubated for $2 \mathrm{~d}$ at $33^{\circ} \mathrm{C}$ in the dark and then transferred to $25^{\circ} \mathrm{C}$ until plants formed. Interestingly, based on the morphological and cytological observations, critical developmental transitions in embryos were discovered at 2 (T1), 10 (T2), 20 (T3), 30 (T4) and 60 (T5) d of culture. Fresh unpollinated ovaries before culture were named T0 (Fig. 1). At T0, fresh unpollinated ovaries were selected, in which the ovules were obvious (Fig. 1a) and the embryo sacs were mature (Fig. 1a1).At T1, heat shock stress induced the embryogenesis of cucumber (Fig. 1b). The most obvious sign that referred to the development of the embryo was the enlargement of the cells in the embryo sac (Fig. 1b1). The enlargement of microspores have been correlated with embryogenic potential acquisition during induction of androgenesis in many crop species [26 27]. After culturing for $2 \mathrm{~d}, 4 \mathrm{~d}$ and $6 \mathrm{~d}$, the expanded cells formed 2 (Fig. 1b2), 4(Fig. 1b3) and multiple cell structures(Fig. 1b4), respectively. At T2, the explants were cultured for $10 \mathrm{~d}$, the ovules that successfully protruded from the surrounding tissues, and a pro-embryo had formed (Fig. 1c). At T3, after $20 \mathrm{~d}$ of culture, the total number of embryos increased continuously in one ovary slice (Fig. 1d). From T3 to T4 (culture for $30 \mathrm{~d}$ ), the whole embryo had formed, including globular embryos, heart-shaped embryos, torpedo-shaped embryos and cotyledon-shaped embryos (Fig. $1 \mathrm{~g}$ ). At the same time, the color of the embryonic cells appeared green, indicating that the development of plants from the embryo would begin (Fig. 1e). At T5 (60 d after culture), shoots had formed (Fig. 1f).

At T1, ovule enlargement and cell enlargement could be clearly observed, suggesting that the transformation of the development pathway from the gametophyte to the sporophyte was induced by stress and that the stage between T0 and T1 was the key to inducing embryogenesis. After the switching of cell development, embryogenic potential was acquired. Mitosis then occurred continuously to form proembryos, globular embryos, heart-shaped embryos, torpedo-shaped embryos and cotyledon-shaped embryos, similar to zygote development, and this process continued until T4. After $6 \mathrm{~d}$ of culture, the mature embryos developed into shoots. Therefore, we divided the six time points of ovary culture into three stages: T0 to T1 (embryogenesis early stage), T1 to T4 (embryo maturation stage), and T4 to T5 
(shoot formation stage). Transcriptome data were generated via Illumina II HiSeq ${ }^{\mathrm{TM}} 2000$ sequencing, and the statistics of RNA-seq alignment were shown in Table S1.

\section{Validation of differentially expressed genes}

Validation of the Illumina sequencing data and the expression patterns of the DEGs revealed by RNA-seq was performed to examine the expression patterns of $10 \mathrm{DEGs}$, including 7 genes involved in plant hormone signal transduction and 3 plant-pathogen interaction genes. The results showed that the relative expression levels revealed by RNA-seq and qRT-PCR were closely correlated (Pearson's $r=0.53,0.77,0.57$, $0.74,0.79,0.69,0.81,0.81,0.86,0.62,0.81)$. The fold changes in the qRT-PCR analysis were different from those in the RNA-seq analysis, which might be due to the difference in sensitivity between the qRTPCR analysis and the RNA-seq technique. However, the qRT-PCR analysis showed that the up- and downregulation trends of the differential gene expression were consistent with those of the RNA-seq analysis (Fig. 2).

\section{Expression of embryogenesis-related genes in cucumber ovary culture}

At the early stage of embryogenesis, after heat shock stress, ovule enlargement was obvious (Fig. 1b). Cytological observations also showed that one of the cells in the embryo sac expanded (Fig. 1b1), suggesting acquisition of embryogenic potential.

The differentially expressed genes (DEGs) at this stage (T0 vs T1) were identified as comprising 3468 upregulated genes and 3065 down-regulated genes (Fig. 3). We performed a GO enrichment analysis of these genes, and the results showed that the proteins encoded by these genes were assigned to 4 biological processes, 3 molecular functions and 9 cellular components (Table S2). Different genes were involved in different biological processes, and the same gene was involved in a variety of biological processes. The majority of DEGs were involved in the 'single-organism process' (G0:0044699) and the 'oxidation-reduction process' (GO:0055114). They were mainly distributed among the terms 'membrane' (G0:0016020), 'membrane part' (GO:0044425), 'intrinsic component of membrane' (GO:0031224) and 'integral component of membrane' (G0:0016021), having good molecular function in oxidoreductase activity (GO:0016491). Among the DEGs, the expression of related genes involved in the functional classification might play an important role in early embryogenesis.

To compare and summarize the results of this stage, we performed a pathway analysis to identify potential target genes. Based on the KEGG database, the pathway enrichment analysis of these genes revealed significant involvement in 8 distinct pathways (Fig. 4): pathways involving plant hormone signal transduction, phenylpropanoid biosynthesis, plant-pathogen interaction, glutathione metabolism, cysteine and methionine metabolism, drug metabolism-cytochrome P450, phenylalanine metabolism and metabolism of xenobiotics by cytochrome P450. 


\section{Plant hormone signal transduction genes}

The DEGs were significantly enriched in the plant hormone signal transduction pathway (Ko04075), and a large number of genes encoding cytokinin transfer proteins (Csa2M373410.1, Csa6M067360.1, Csa7M452370.1), cytokinin response proteins (Csa1M006300.1, Csa3M822100.1, Csa4M436980.1, Csa5M223020.1, Csa5M434550.1, Csa5M603910.1, Csa5M623800.1, Csa6M383530.1), ethylene-binding proteins (CsaUNG009930) and ethylene-responsive protein transcription factors (Csa3M389850.1) were detected, which were significantly up-regulated after heat treatment. Moreover, the partially up-regulated DEGs encoding auxin influx carriers, auxin-responsive proteins, SAUR family proteins, abscisic acid receptor proteins, serine/threonine-protein kinases, ABA-responsive element binding factors, and brassinosteroid signal-responsive protein kinases were significantly enriched in 8 pathways, some of which involved tryptophan metabolism as well as zeatin, carotene, and brassinosteroid biosynthesis, suggesting that hormone responses and hormone signal transduction were closely related to stressinduced embryogenesis. The up-regulated genes encoding major enzymes and receptor proteins involved in the plant hormone signal transduction pathway were expressed during the whole stage of ovary culture (Fig. 5). Most of the genes were expressed dynamically after their up-regulated expression during embryogenesis. Only two genes (Csa6M147590.1, Csa3M389850.1) were up-regulated the stage of embryo initiation; both almost no expression in the later stages. Csa6M147590.1 and Csa3M389850.1 encode auxin-induced proteins and ethylene-responsive transcription factors, respectively, indicating that they might be closely related to embryogenesis.

\section{Stress response proteins related to plant defense mechanisms}

DEGs were significantly enriched in the plant-pathogen interaction pathway, which was related to plant defense mechanisms and complex physiological responses to heat shock-induced embryogenesis. In this regulatory pathway, the expression of Pti1 (Csa7M420160.1), HSP90 (Csa3M183950.1), EDS1

(Csa1M006320.1) and other related protein genes were up-regulated. Heat shock protein 90 (HSP90) was a protein that was up-regulated under heat stress. This gene had been highly conserved during evolution and had plant defense functions.

\section{Response of genes involved in microtubule organization in cucumber ovary culture}

In the stage of embryo maturation, the gametophyte development pathway switched to the sporophyte development pathway, in which the cells enlarged and initiating mitosis, forming 2-cell, 4-cell and multicellular pro-embryos after heat stress (Fig. 1b1 b4); afterward, globular embryos, heart-shaped embryos, torpedo-shaped embryos and cotyledon embryos were formed (Fig. 1g). The DEGs analyses of T1 vs T2, T2 vs T3 and T3 vs T4 revealed 480 continuously expressed genes. Additionally, the numbers 
of uniquely expressed genes between T1 and T2, T2 and T3 and T3 and T4 were 2236, 371 and 1558, respectively (Fig. 6).

GO categories of the 480 continuously expressed genes were significantly assigned to 2 biological processes, including cell movement or subcellular component (G0:0006928) and microtubule-based movement (GO:0007018), which were mainly associated with microtubules (G0:0005874), supramolecular fibers (G0:0099512) and polymeric cytoskeletal fibers (GO:0099513). Subsequently, proteins encoded by these genes were classified into 11 functional categories, including protein complex binding (GO:0032403), microtubule binding (GO:0008017), tetrapyrrole binding (GO:0046906), tubulin binding (GO:0015631), microtubule motor activity (G0:0003777), motor activity (G0:0003774), macromolecular complex binding (G0:0044877), heme binding (G0:0020037), oxidoreductase activity (G0:0016491), iron ion binding (G0:0005506) and oxidoreductase activity(G0:0016491), acting on paired donors or the molecular incorporation of oxygen (G0:0016705) (Table S3). This findings indicated that, during certain stages, the cytoskeleton structure was continuously built and maintained by the action of microtubule binding proteins and enzyme modifications, providing the basis for positioning the various organelles and implementation functions, which ensured the orderly activities in various cells in time and space.

To determine the involvement of these differentially expressed genes in embryo development, we performed a pathway analysis to identify the potential target genes, and 17 significant pathways were obtained by mapping to the KEGG database (Fig. 7): protein processing in the endoplasmic reticulum, phenylpropanoid biosynthesis, photosynthesis-antenna proteins, limonene and pinene degradation, meiosis-yeast, the estrogen signaling pathway, cell cycle, cell cycle-yeast, diterpenoid biosynthesis, chloroalkane and chloroalkene degradation, carotenoid biosynthesis, progesterone-mediated oocyte maturation, glycerolipid metabolism, histidine metabolism, fatty acid degradation, antigen processing and presentation, and ascorbate and aldarate metabolism. Among them, the pathways of protein processing in the endoplasmic reticulum and phenylpropanoid biosynthesis were the most significant.

\section{Expression of main oxidation-reduction and metabolic process-related genes in cucumber ovary culture}

In the stage of shoot formation, the embryos further differentiated into shoots (Fig. 1f). In total, 3320 genes were differentially expressed between T4 and T5, among which 1383 genes were up-regulated and 1837 were down-regulated in T5 (Fig. 3). Next, we performed an enrichment analysis of the genes using Gene Ontology (GO), which revealed 18 biological processes, 15 molecular functions and 5 cellular components (Table S4). The terms annotated under the biological process category mainly included oxidation-reduction processes (GO: 0055114), the regulation of primary metabolic processes (GO: 0080090), the regulation of cellular metabolic processes (GO: 0031323), and the regulation of macromolecule metabolic processes (GO: 0060255). The molecular function category mainly included the terms oxidoreductase activity (GO: 0016491) and DNA binding (GO: 0003677). The cellular 
component category mainly included extracellular region (GO: 0005576). The development of the ovary culture was mainly focused on the process of oxidation-reduction and metabolism.

The DEGs were subsequently annotated using the KEGG database to identify pathway enrichments. A variety of pathways were found to be significantly enriched (Fig. 8), including those involved in phenylpropanoid biosynthesis; plant hormone signal transduction; stilbenoid, diarylheptanoid and gingerol biosynthesis; metabolism of xenobiotics by cytochrome P450; drug metabolism-cytochrome P450; flavonoid biosynthesis; phenylalanine metabolism; starch and sucrose metabolism; and zeatin biosynthesis. Most of the differentially expressed genes were mainly enriched in phenylpropanoid biosynthesis, plant hormone signal transduction, phenylalanine metabolism, and starch and sucrose metabolism. Pathways involving phenylpropanoid biosynthesis and phenylalanine were important for metabolizing secondary metabolites in plants and were closely related to cell differentiation and pigmentation in plant development. In the plant hormone signal transduction pathway, the expression of an auxin response factor, the gibberellin receptor GID1, ethylene-responsive transcription factor 1 ( $E R F 1$ ) and cyclin D3 were up-regulated, promoting plant development and maturation, cell enlargement and division as well as promoting the development of stems. In addition, the DEGs involved in starch and sugar metabolism were also significantly enriched and mainly encoding 3- $\beta D$ glucosidase, T6Ps, GlgB, endoglucanase and alpha-trehalase, which satisfied the requirements of embryo growth and development.

\section{Discussion}

Many previous experiments have shown that early embryogenesis of microspore cultures can be divided into three main phases: acquisition of embryogenic potential, initiation of cell division, and pattern formation [27]. In the present study, the whole process was investigated from acquisition of embryogenic potential to plant regeneration. We divided the ovary culture into three stages. In the early stage of embryogenesis, the acquisition of embryogenic potential by stress (e.g., low or high temperature and hormone induction) was observed together with the repression of gametophytic development, leading to the dedifferentiation of cells. In the embryo maturation stage, cell divisions gave rise to the formation of pro-embryos (cell clumps), globular embryos, heart-shaped embryos, torpedo-shaped embryos and cotyledon embryos (mature embryos). In the stage of shoot formation, mature embryos developed into shoots. There are active molecular events that regulate embryo development at different stages of development.

\section{Embryogenesis-related genes are expressed in cucumber ovary culture}

The embryogenic ability and transformation of somatic cells were regulated by various plant hormones, such as auxin, abscisic acid, cytokinin and ethylene [28]. Moreover, the synthesis of auxin and ethylene increased significantly after ovary pollination and fertilization [29]. In normal growth, mitotic asymmetry 
of fertilized eggs was found in the gametophyte development pathway. Previous work using molecular and genetic approaches has identified auxin as a critical signal for the proper development of the asymmetric structure of the female gametophyte in Arabidopsis [30]. In in vitro culture, a certain stress condition is needed to block the development direction of the original gametophyte, followed by turning into the direction of the sporophyte and carrying on the symmetry splitting to eventually lead to embryogenesis [31]. In ovary culture of cucumber, heat shock pretreatment, silver nitrate, genotype and hormone combination factors could play key roles in embryo and callus production independently and simultaneously [32]. In the ovary culture of linseed, cultivar, combination of growth regulators, type of carbohydrates and their interaction significantly influenced callus induction and shoot formation frequency, and a relatively high shoot regeneration frequency was obtained when the medium was supplemented with TDZ and NAA [33]. These results implied that the expression of specific genes in embryogenesis was activated by exogenous hormone regulation, which laid the foundation for DNA replication in the cell division stage.

In our study, a large number of DEGs were enriched in the plant hormone signal transduction pathway during the stress process of embryogenesis. The pathway annotation obtained by KEGG analysis showed that phytohormones such as cytokinin and ethylene were significantly up-regulated in multiple biosynthesis and metabolic pathways, while up-regulated and down-regulated genes related to auxin and abscisic acid both existed. Generally, high-level endogenous cytokinin and low-level endogenous ethylene are beneficial for the acquisition of embryogenic ability. Embryogenesis is the comprehensive performance of interactions among different hormones, and all kinds of endogenous hormones show dynamic changes. The up-regulated expression of the main enzymes and receptor proteins in the plant hormone signal transduction pathway could promote embryogenesis, indicating that the high expression of related genes may play important roles in the process of switching from the gametophyte to the sporophyte development pathway. In this pathway, we found two genes related to hormone regulation that were highly expressed only at the stage of early embryo development (Csa6M147590.1 and Csa3M389850.1);moreover, the functional categories of their specific functions and the location of the regulatory pathways were identified, thus laying an important theoretical basis for the elucidation of the mechanism.

Heat shock protein 90 (HSP90) is an evolutionarily conserved molecular chaperone induced by abiotic stress. HSP90 plays an important role in cell cycle control, genomic silencing, protein transduction and signal transduction[20]. The $H S P 90$ chaperone is involved in maintaining phenotypic plasticity and developmental stability [34-35]. Previous studies have shown that HSP genes were specifically expressed in the spore stress-induction process of many crop species [36-38]. HSPs had been described as genes associated with the reprogramming phase and the early stages of embryogenesis [39]. After heat shock stress treatment, we found that 26 up-regulated genes encoded proteins and transcription factors related to heat shock, and HSP90 (Csa3M183950.1) was involved in the regulation of the hypersensitive response in the plant and pathogen interaction pathway. The expression of these genes might play a regulatory role in the process of embryogenesis. 
The $B B M$ gene was the first key gene to be isolated in the process of spore cell division; which was first expressed in zygotic embryogenesis and microspore embryogenesis $[14,40]$. We found that two $B B M$ genes (Csa3M827310.1, Csa3M827320.1) were up-regulated at the beginning of embryogenesis and were subsequently down-regulated. In addition, AGL15a member of the MADS family, was also considered a regulatory protein that acts at the start of cell division [13]. We found that the AGL gene (Csa3M258140.1) was up-regulated in our study, indicating that all three of these genes play important roles in embryogenesis. We considered that $B B M, H S P 90$ and $A G L$ might be the critical genes involved in the induction of embryogenesis by ovary culture in cucumber.

\section{Microtubule organization genes play an important role in the embryogenesis of cucumber ovary culture}

There is a similar process between gametophyte embryogenesis and zygotic embryogenesis, and the only difference is that the former occurs in sex cells, while the latter occurs in fertilized egg cells. The process of gametophyte embryogenesis development is similar to that of zygote differentiation into embryos. Microtubules play a transport role in cells, participating in the construction of cell walls and promoting cell differentiation and division. Electron microscope-based observations of carrot culture showed that the appearance of microtubules was accompanied with the formation of somatic embryos [41]. The different patterns of microtubule organization in the cells of the mature embryo sac reflect their structural adaptations for their future function [42].

In our study, after embryogenic potential was acquired, the different embryo shapes formed through active cell metabolism and rapid cell division. GO analysis showed that in different embryo periods continuously expressed genes participated in microtubule-based movement and cell or subcellular component processes, providing a good function of protein complex binding, microtubule binding, tetrapyrrole binding, tubulin binding and other microtubule activities; these genes mainly participated in protein processing of the endoplasmic reticulum and phenylpropanoid biosynthesis. We considered that the cellular reprogramming and morphological changes in embryos were controlled by microtubule organization genes.

\section{Expression of main oxidation-reduction and metabolic process-related genes in cucumber ovary culture}

Mature embryos are further cultured to form shoots, and at this stage, many biological processes are involved. GO analysis showed that differentially expressed genes participated in the oxidation-reduction process, a variety of metabolic processes, biosynthesis processes and the response to auxin, together with the molecular functions of oxidoreductase activity, binding capacity, catalytic activity, transporter activity, transcription factor activity and so on. Among them, the regulation of transcription, DNA template (GO: 0006355), the regulation of RNA biosynthetic processes (GO: 2001141), the regulation of RNA 
metabolic processes (GO: 0051252), DNA binding (GO: 0003677), transcription factor activity (GO: 0003700), and sequence-specific DNA binding (GO: 0043565) lay a foundation for cell division and differentiation. In addition, two processes, cellular response to auxin stimulus (GO: 0071365) and response to auxin (GO: 0009733), might promote the embryo to form shoots.

At the stage of shoot formation, a large number of transcription factors were expressed. The first constitutes transcription factors that contain a B3 domain [43]. These transcription factors can encode regulatory proteins involved in the embryonic development process, maintaining embryo development during late embryonic development [43, 44]. In our study, total of 6 transcription factors(Csa2M359980.1, Csa2M292240.1, Csa5M608380.1, Csa6M489980.1, Csa6M489940.1 and CsaUNG031640) that contain a B3 domain were up-regulated.The second was the AIL gene from the AP2/ERF family, which is involved in key developmental processes throughout the whole plant life cycle. Some genes in the AP2/ERF gene family are expressed in many tissues and participate in many plant development processes, such as embryogenesis and shoot development $[14,45)$. In addition, we found that the expression levels of 9 genes (Csa1M423190.1, Csa3M114480.1, Csa3M652380.1, Csa3M114470.1, Csa4M644740.1, Csa5M175970.1, Csa5M608380.1, Csa6M496390.1,and CsaUNG031640) in theAP2/ERF family were upregulated. Furthermore, WUS homologous domain proteins not only alter the cell fate of the shoot and flower meristem but also promote the development of somatic embryos into seedlings. The function of WUS proteins has no direct connection with the characteristics of the embryo but will alter the development state of the tissue by maintaining cells in an undifferentiated state in response to different stimuli [46]. The ability to transform the vegetative growth phase to the embryonic stage by WUS, as well as to eventually form somatic cells, indicates that this homologous domain protein also plays an important role in embryo maturation in addition to its role in the development of the meristem [47]. During this stage, two genes encoding WUS homologous domain proteins (Csa6M301060.1) and (Csa6M505860.1) were up-regulated. We considered that those homologous domain proteins might directly or indirectly regulate shoot formation.

\section{Conclusion}

Several studies have reported on the embryogenesis of ovary culture in cucumbers. However, the mechanism that drives the process from embryogenic acquisition to the formation of embryos and plant regeneration is not well understood. In this study, we explored embryogenesis mechanism of ovary culture in cucumber. Inducing cucumber embryogenesis could be divided into three stages: early embryogenesis, embryo maturation (from proembryos to cotyledon embryos) and shoot formation (Fig. 9a).

The early stage of embryogenesis was the turning point for the formation of embryos, which had experienced dedifferentiation and loss of photosynthetic capacity, requiring the provision of exogenous nutrients and carbon sources such as plant hormones and sucrose in the media. Some physical factors, such as temperature, light quality, photoperiod and the presence of specific hormones, could affect the 
ability of the embryo sac to adapt to these conditions and survive the developmental transition. These dynamic changes were helpful for cell physiology reprogramming, metabolic alterations, revival of cell division and differentiation, morphogenesis and so on. Therefore, the cells of the embryo sac began to divide by dedifferentiation and started to form cell clumps (Fig. 1b1 b4). Although there was no obvious change in appearance, the metabolism of some macromolecules in the cells changed markedly. A large number of hormone-related genes, cell protection-related genes, and some unique protein kinases and transcription factors (Csa6M147590.1 and Csa3M389850.1) were expressed only at the stage of early embryo development. The reported embryogenesis-related genes BBM, HSP90 and AGL were also actively expressed during this stage (Fig. 9b).

In the stage of embryo maturation, $\mathrm{GO}$ analysis showed continuously expressed genes participated in microtubule-based movement, movement of the cell or subcellular component processes, giving a good function of protein complex binding, microtubule binding, tetrapyrrole binding, tubulin binding and other microtubule activities, which are involved in protein processing in the endoplasmic reticulum and phenylpropanoid biosynthesis(Fig. 9b).

Shoot formation was regulated by 6 transcription factors that contain a B3 domain, total of 9 genes in the AP2/ERF family and 2 genes encoding WUS homologous domain proteins (Fig. 9b).

\section{Methods}

\section{Plant materials}

'SG033' ( $F_{1}$ cultivar of Kunming Huaxing seed Industry Co., Ltd., Kunming, Yunnan) was used for ovary culture; this material had a high embryo rate after a large number of screenings. Cucumber plants from southern China were cultivated and stored in our lab. The plants were grown in a greenhouse with a $12 \mathrm{~h}$ photoperiod, a mean daily air temperature of $25 / 15^{\circ} \mathrm{C}$ (day/night), a relative humidity of $85 \%$ and a photosynthetic photo flux density of $500 \mu \mathrm{mol} \cdot \mathrm{m}^{-2} \cdot \mathrm{s}^{-1}$ at the Horticulture Institute of Guizhou Academy of Agricultural Sciences, Guizhou, China. Ovaries were collected from 'SG033' for one month after the first anthesis flower appeared.

\section{Ovary culture}

Ovaries were harvested at $6 \mathrm{~h}$ before anthesis, after treated for $24 \mathrm{~h}$ in a refrigerator at $4{ }^{\circ} \mathrm{C}$, which papilloma was removed. The ovaries were then sterilized in $75 \%$ ethanol for $30-60$ s and rinsed in sterile distilled water 3 times, followed by soaking in a $0.5 \%$ sodium hypochlorite for 20 min and then rinsing in sterile distilled water 3 times. The ovaries were cut into small round slices of $2 \mathrm{~mm}$ under sterile conditions and then placed on $30 \mathrm{~mL}$ of solid media in cylindrical flasks. In all experiments, MS medium was used as a basal medium; it was supplemented with $0.06 \mathrm{mg} \cdot \mathrm{L}^{-1} \mathrm{TDZ}$ and $3 \%(\mathrm{w} / \mathrm{v})$ sucrose and was solidified with $7 \%(\mathrm{w} / \mathrm{v})$ agar. The $\mathrm{pH}$ of the medium was adjusted to 5.9 before autoclaving at $116^{\circ} \mathrm{C}$ 
and $1.1 \mathrm{~kg} / \mathrm{cm}^{2}$ for $30 \mathrm{~min}$. All materials were treated with high temperature of $33^{\circ} \mathrm{C}$ for $2 \mathrm{~d}$, after which recovery growth was allowed until shoot formation occurred at $25^{\circ} \mathrm{C}$ under a $16 / 8 \mathrm{~h}$ (light/dark) photoperiod with a 4000 Ix light intensity.

\section{RNA isolation}

The materials were harvested separately at the following time points: T0 (the ovules were cultured for $0 \mathrm{~d}$, fresh unpollinated ovaries), T1 (the ovules were cultured for $2 \mathrm{~d}$ ), T2 (the embryos were cultured for $10 \mathrm{~d}$ ), T3 (the embryos were cultured for $20 \mathrm{~d}$ ), T4 (the embryos were cultured for $30 \mathrm{~d}$ ), and T5 (the shoots after culture for $6 \mathrm{~d}$ ). These materials were stored at $-80^{\circ} \mathrm{C}$ for RNA extraction, and the remaining materials were maintained in culture to observe plantlet regeneration. Furthermore, all experimental procedures, such as culture medium replacement and sample collection, were performed under similar conditions to minimize possible circadian effects. Ovules at T0 and T1 were extracted by hand under a stereoscopic microscope, and embryo-like structures with integuments were selected directly at the time points from T2 to T5.

As described above, samples were collected from six time points of ovary culture for RNA-seq analysis. For each sample, the ovules or embryo-like structures were immersed in liquid nitrogen in a mortar and ground into powder (three biological replicates per sample). Total RNA was isolated using TRIzol (Invitrogen), and DNase I (Fermentas) digestion was performed for $30 \mathrm{~min}$ at $25^{\circ} \mathrm{C}$ to remove DNA, according to the manufacturer's instructions. The integrity and quality of the total RNA were checked using a NanoDrop 1000 spectrophotometer and formaldehyde-agarose gel electrophoresis. RNA was used only when the $\mathrm{OD}_{260}: \mathrm{OD}_{280}$ ratio was above 1.8 .

\section{Transcriptome analysis}

Transcriptomes were analyzed by an Illumina HiSeq ${ }^{\mathrm{TM}} 2000$. The reads with more than $10 \%$ unknown bases and those of low quality were removed from the raw sequencing data using the software Illumina GA Pipeline (v1.6). The filtered reads were aligned to the cucumber Chinese long v2 genome using TopHat2 (http://tophat.cbcb.umd.edu/) software. The reference genome and gene database information were obtained from the public website: http://cmb.bnu.edu.cn/Cucumis_sativus_v20/ [42]. Differential expression analysis was determined using DESeq (version 1.18.0). The resulting $P$ values were adjusted by using Benjamini and Hochberg's approach for controlling the false discovery rate. Genes with an adjusted $P$ value of $<0.05$ and an absolute value of |log2fold change $\geq 1 \mid$ according to DESeq were considered differentially expressed. GO annotation was performed using Blast2GO software (GO association was performed by a BLASTX search against the NCBI NR database). GO enrichment analysis of differentially expressed genes (DEGs) was then performed via the BiNGO plugin for Cytoscape. Overrepresented GO terms were identified using a hypergeometric test with a significance threshold of 0.05 after the Benjamini-Hochberg FDR correction. KEGG enrichment analysis of the differentially 
expressed genes was performed using the KOBAS (2.0) [48] software. A ' $P$ value $\leq 0.05$ ' was used as the threshold to judge the significantly enriched pathways of the differentially expressed genes.

\section{Real-time quantitative PCR}

Ten DEGs were selected from all the DEGs for analysis using real-time quantitative PCR (qRT-PCR). For this step, the total RNA was treated with the DNase I enzyme and subsequently converted to single-strand cDNA by applying the GoScript ${ }^{\mathrm{TM}}$ Reverse Transcription System (Promega) according to the manufacturer's protocol. The specific gene primers were designed using Primer 5.0 according to the cDNA sequences in Table S5. Actin was used as the internal control to normalize small differences in template quantities. Quantitative real-time PCR was performed with GoTaq qPCR Master Mix (Promega) in a BioRad iQ1 real-time PCR system (Bio-Rad), and the collected data were analyzed using the $2^{-\Delta \Delta C t}$ method.

\section{Abbreviations}

DH, Double haploid; DEG, Differentially expressed genes; qRT-PCR, Quantitative real-time PCR; SSR, Simple sequence repeats; FDR, False discovery rate; $A G L 15$, Agamous-like15; AP2/ERF, Ethyleneresponsive element-binding factor; $B B M$, Baby boom; $H S P$, Heat shock proteins; Pti1, Pto-interacting protein 1; AlL,Aintegumenta-like; $L E C$, Leafy Cotyledon; GID1, gibberellin receptor, $E R F 1$, ethyleneresponsive transcription factor1; WUS, WUSCHEL; TDZ, thidiazuron;

3- $\beta D$ glucosidase, 3-beta-D-glucosidase; T6Ps, Trehalose 6-phosphate synthase; GlgB, 1,4-alpha-glucan branching enzyme.

\section{Declarations}

\section{Ethics approval and consent to participate}

Not applicable.

\section{Consent for publication}

Not applicable.

\section{Availability of data and materials}

The data sets supporting the results of this article are included within the article and its additional files.

\section{Competing Interests}


The authors declare that they have no conflict of interest.

\section{Funding}

The financial support from National Natural Science Foundation of China (No. 31460515), Jiangsu Agricultural Innovation of New Cultivars (No. PZCZ201719) هGuizhou Science and Technology Support Plan $₫ N 0.20192259$ and Special Fund for Agro-Scientific Research of Guizhou Academy of Agricultural Sciences (No. 2015-19) are deeply appreciated. Guizhou Construction of Genetics and Breeding Laboratory of Vegetable Industry System(2019-0102).

\section{Author contributions}

JFC guide and designed the research. YD , BT, WYF, LT, LZ , XZ and JL performed the experiment, analyzed, interpreted date, and rote the manuscript. All authors reviewed and contributed to draft the manuscript. All authors read and approved the final manuscript.

\section{Acknowledgements}

The authors would like to acknowledge the Dr Tan (Institute of Horticulture, Guizhou Academy of Agricultural Sciences, Guiyang , China) for critical reading of the manuscript, Jiaji Zhang( Personal Biotechnology Corporation, Shanghai, China) for their efforts in bioinformatics analysis and Springer Nature Author Services for writing services.

\section{References}

1. Guha S, Maheshwari SC. In vitro production of embryos from anthers of datura. nature. 1964;204:497.

2. Malik MR, Wang F, Dirpaul JM, Zhou N, Polowick PL, Ferrie, AMR, Krochko JE. Transcript profiling and identification of molecular markers for early microspore embryogenesis in Brassica napus. Plant Physiology. 2007;144:134-154.

3. Bhat JG, Murthy HN. Factors affecting in-vitro gynogenic haploid production in niger (Guizotia abyssinica(L. f.) Cass.). Plant Growth Regulation. 2007;52:241-248.

4. Metwally EI , Moustafa SA, El-Sawy BI, Haroun SA, Shalaby TA. Production of haploid plants from in vitro culture of unpollinated ovules of Cucurbita pepo. Plant Cell Tissue and Organ Culture. 1998;52:117-121.

5. Gémes-Juhász A, Balogh P, Ferenczy AZ, Kristóf. Effect of optimal stage of female gametophyte and heat treatment on in vitro gynogenesis induction in cucumber (Cucumis sativus L.). Plant Cell Reports. 2002;21:105-111. 
6. Halit Y, Nebahat S. A new method for haploid muskmelon (Cucumis melo L.) dihaploidization. Scientia Horticulturae. 2003;98:277-283.

7. Shalaby TA. Factors affecting haploid induction through in vitro gynogenesis in summer squash (Cucurbita pepo L.). Scientia Horticulturae. 2007;115:1-6.

8. Diao WP, Jia YY, Song H, Zhang XQ, Lou QF, Chen JF. Efficient embryo induction in cucumber ovary culture and homozygous identification of the regenetants using SSR markers. Scientia Horticulturae. 2009;119:246-251.

9. Li JW, Si SW, Cheng JY, Li JX, Liu JQ. Thidiazuron and silver nitrate enhanced gynogenesis of unfertilized ovule cultures of Cucumis sativus. Biologia Plantarum. 2013;57:164-168.

10. Plapung P, Khumsukdee S, Smitamana P. Development of cucumber lines resistant to cucumber mosaic virus by ovule culture. International Journal of Agricultural Technology. 2014;733-741.

11. Tantasawat PA, Sorntip A, Poolsawat O, Chaowiset W, Pornbungkerd P. Evaluation of factors affecting embryo-like structure and callus formation in unpollinated ovary culture of cucumber(Cucumis sativus). International Journal of Agriculture \& Biology. 2015;17:613-618.

12. Touraev A, Vicente $O$, Heberle-Bors E. Initiation of microspore embryogenesis by stress. Trends in Plant Science. 1997;2:297-302.

13. Perry SE, Fernandez DE. The MADS-domain protein AGAMOUS-like 15 accumulates in embryonic tissues with diverse origins. Plant Physiology. 1999;120:121-129.

14. Boutilier K, Offringa R, Sharma VK, Kieft $H$, Ouellet T, Zhang L, Hattori J, Liu CM, van Lammeren AAM, Miki BLA, Custers JBM, van Looleren Campagne MM. ectopic expression of BABY BOOM triggers a conversion from vegetative to embryonic growth. Plant Cell. 2002;14:1737-1749.

15. Maraschin SF, Priester WD, Spaink HP, Spaink, Wang M. Androgenic switch: an example of plant embryogenesis from the male gametophyte perspective. Journal of Experimental Botany. 2005;56:1711-1726.

16. Hosp J, Tashpulatov A, Roessner U, Barsova E, Katholnigg H, Steinborn R, Melikant B, Lukyanov S, Heberle-Bors E, Touraev A. Transcriptional and metabolic profiles of stress-induced, embryogenic tobacco microspores. Plant Molecular Biology. 2007;63:137-149.

17. Rosa Angélica SánchezDíaz, Ana María Castillo, María Pilar Vallés. Microspore embryogenesis in wheat: new marker genes for early, middle and late stages of embryo development. Plant Reproduction. 2013;26:287-296.

18. Irikova T, Grozeva S, Denev I. Identification of BABY BOOM and LEAFY COTYLEDON genes in sweet pepper (Capsicum annuum L.) genome by their partial gene sequences. Plant Growth Regulation. 2012; 67:191-198.

19. Bélanger S, Marchand S, Jacques PÉ, Meyers B, Belzile F. Differential expression profiling of microspores during the early stages of isolated microspore culture using the responsive barley cultivar gobernadora. Genes Genomes Genetics.2018;8:1603-1614

20. Zhang J , Li J , Liu B , Zhang L, Chen J, Lu M. Genome-wide analysis of the populus HSP90 gene family reveals differential expression patterns localization and heat stress responses. BMC 
Genomics. 2013;14:532-546.

21. Lv J , Qi J , Shi Q, Shen D, Zhang S, Shao G, Li H, Sun ZY, Weng Y, Gu XF, Li XX, Zhu XG, Zhang JZ, van Treuren R, van Dooijeweert W, Zhang ZH, Huang S. Genetic diversity and population structure of cucumber (Cucumis sativus L.). PLoS ONE. 2012;7:e46919.

22. Qing ZW, Xin M, Liu D, Zhang YJ, Wang XG, Zhou XY. A new cucumber $F_{1}$ hybrid 'dongnong 812 '. Chinese Vegetables. 2018;5:71-73.(in Chinese)

23. Golabadi M, Golkar P, Eghtedary AR. Assessment of genetic variation in cucumber (Cucumis sativus L.) genotypes. European Journal of Experimental Biology. 2012;2:1382-1388.

24. Wang X, Bao K, Reddy UK, Bai Y, Hammar SA, Jiao C, Wehner TC, Ramírez-Madera AO, Weng Y, Grumet R, Fei Z. The USDA cucumber (Cucumis sativus L.) collection: genetic diversity, population structure, genome-wide association studies, and core collection development. Horticulture Research. 2018;5:64-67

25. Chen JF, Cui L, Malik AA, Kere George Mbira. In vitro haploid and dihaploid production via unfertilized ovule culture. Plant Cell Tissue and Organ Culture. 2011; 104:311-319.

26. Hoekstra S, Hoekstra IR, Hoekstra RA, Hoekstra E. The Interaction of 2, 4-D application and mannitol pretreatment in anther and microspore culture of Hordeum vulgare L. cv. Igri. Journal of Plant Physiology. 1996;148:696-700.

27. Maraschin, SF. Androgenic switch: an example of plant embryogenesis from the male gametophyte perspective. Journal of Experimental Botany. 2005;56:1711-1726.

28. Ikeda-Iwai M, Umehara M, Satoh S, Kamada H. Stress- induced somatic embryogenesis in vegetative tissues of Arabidopsis thaliana. Plant Journal. 2003;34:107-114.

29. Mól R, Filek M, Machackova I, Matthys-Rochon E. Ethylene synthesis and auxin augmentation in pistil tissues are important for egg cell differentiation after pollination in maize. Plant \& Cell Physiology. 2004;45:1396-1405.

30. Pagnussat GC, Alandetesaez M, Bowman JL, Sundaresan v. Auxin-dependent patterning and gamete specification in the Arabidopsis female gametophyte. Science. 2009;324:1684-1689.

31. Fan Z, Armstrong KC, Keller WA. Development of microspores in vivo, and in vitro, in Brassica napus L. Protoplasma. 1988;147:191-199.

32. Golabadi M, Ghanbari Y, Ghanbari S, Keighobadi K. Embryo and callus induction by different factors in ovary culture of cucumber. Journal of Applied Botany \& Food Quality. 2017;90:68-75.

33. Aušra B, Natalija B, Ramunè M. Genotypic and exogenous factors affecting linseed ovary culture. Zemdirbyste. 2017;104:243-248.

34. Hahn A, Bublak D, Schleiff E, Scharf KD. Crosstalk between Hsp90 and Hsp70 Chaperones and Heat Stress Transcription Factors in Tomato. Plant Cell. 2011; 23:741-755.

35. Sangster TA, Queitsch C. The HSP90 chaperone complex, an emerging force in plant development and phenotypic plasticity. Current Opinion in Plant Biology. 2005;8:86-92. 
36. Zarsky V, Garrido D, Eller N, Eller N, Tupy J, Vicente O, Schoffl F. The expression of a small heat shock gene is activated during induction of tobacco pollen embryogenesis by starvation. Plant Cell \& Environment. 2010;18:139-147.

37. Binarova P, Hause G, Cenklová V, Cordewener JHG, Looderen Campagne MM. A short severe heat shock is required to induce embryogenesis in late bicellular pollen of Brassica napus L.. Sexual Plant Reproduction. 1997; 10:200-208.

38. Sabehat A, Weiss D. Expression of small heat-shock proteins at low temperatures: A possible role in protecting against chilling injuries. Plant Physiology. 1998;117:651-8.

39. Maraschin SF. Androgenic switch: an example of plant embryogenesis from the male gametophyte perspective. Journal of Experimental Botany. 2005; 56:1711-1726.

40. Pechan PM, Bartels D, Brown DC, Schell J. Messenger-RNA and protein changes associated with induction of Brassica, microspore embryogenesis. Planta. 1991;184:161-165.

41. Halperin W, Jensen WA. Ultrastructural changes during growth and embryogenesis in carrot cell cultures. Journal of Ultrastruct Research. 1967;18:428-443.

42. Huang BQ, Sheridan WF. Female Gametophyte Development in maize: microtubular organization and embryo sac polarity. Plant Cell. 1994;6:845-861.

43. Stone SL, Kwong LW, Yee KM, Yee KM, Pelletier J, Lepiniec L, Fischer RL. LEAFY COTYLEDON2 encodes a B3 domain transcription factor that induces embryo development. Proceedings of the National Academy of Sciences. 2001;98:11806-11811.

44. Lotan T, Ohto M, Yee K M, West MA, Lo R, Kwong RW, Yamagishi, Fischer RL, Goldberg RB, Harada JJ. Arabidopsis LEAFY COTYLEDON1 is sufficient to induce embryo development in vegetative cells. Cell. 1998;93:1195-1205.

45. Riechmann JL, Meyerowitz EM. The AP2/EREBP family of plant transcription factors. Biological Chemistry. 1998;379:633-646.

46. Mayer KF, Schoof H, Haecker A, Lenhard M, Laux T. Role of WUSCHEL in Regulating Stem Cell Fate in the Arabidopsis Shoot Meristem. Cell. 1998;95:805-815.

47. Palovaara J, Hakman I. Conifer WOX-related homeodomain transcription factors, developmental consideration and expression dynamic of WOX2 during Picea abies somatic embryogenesis. Plant Molecular Biology. 2008;66:533-549.

48. Mao X, Cai T, Olyarchuk JG, Wei L. Automated genome annotation and pathway identification using the KEGG Orthology (KO) as a controlled vocabulary. Bioinformatics. 2005;21:3787-3793.

\section{Additional File Legend}

Table S1. Statistics of RNA-Seq alignment

Table S2. GO classification of common expressed genes in gynogenesis stage.

Table S3. GO classification of common expressed genes from embryogenesis to the mature stage. 
Table S4. GO classification of common expressed genes in organogenesis stage.

Table S5. Primers for Real-time quantitative PCR

\section{Figures}

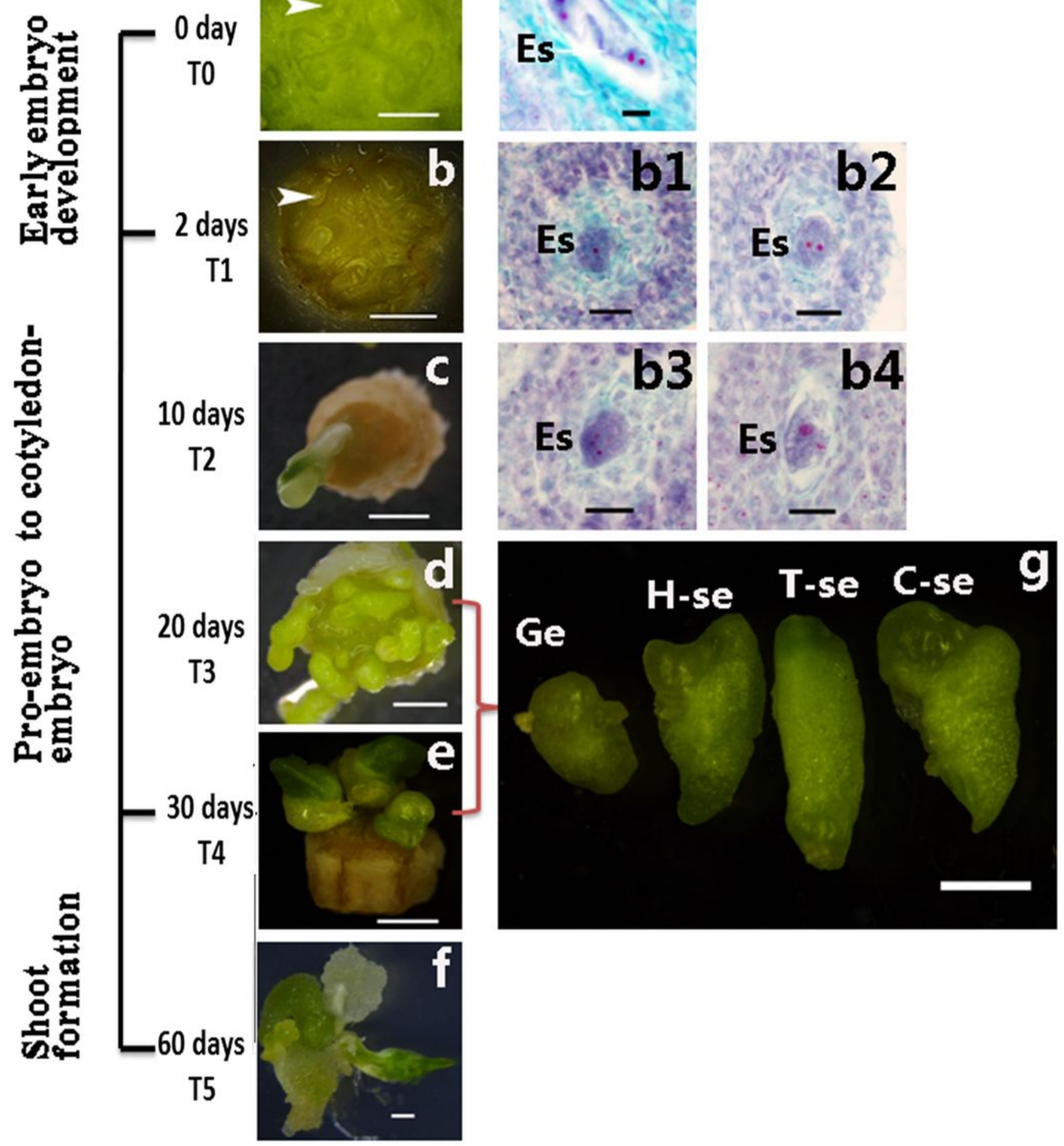

Figure 1 
Embryogenic process of ovary culture in cucumber a-g observation under stereoscopic microscope. a selected fresh unpollinated ovaries $(0 \mathrm{~d}, \mathrm{~T} 0)$. b ovule were treated with the high temperature of $33 \mathrm{oC}$ for 2 $\mathrm{d}$; $\mathrm{c}$ the embryo cultured for $10 \mathrm{~d}$, the ovule enlargement and embryo initiation. $d$ embryos of culturing 10 $d$, an average of 6 embryoids in each slice of ovary; e embryos of culturing $30 \mathrm{~d}$, embryo maturation and cotyledon-embryo formation. $f$ culturing for $60 \mathrm{~d}$, the embryo differentiated into shoot. g globular-embryo switch into cotyledon shape-embryo. Histological observations: the histological sections were stained with Delafield's hematoxylin. a1 multicellular embryo sac before culturing, b1 one of the cells expands in the embryo sac, $2 \mathrm{~d}$ of culture, b2 cell mitosis, $4 \mathrm{~d}$ of culture. b3 continue to be divided into four cells, $6 \mathrm{~d}$ of culture. b4 cell clumps structure, $8 \mathrm{~d}$ of culture. G-e globular embryo, H-se heart-shaped embryo, T-se torpedo-shaped embryo, C-se cotyledon-shaped embryo, E sembryo sac. The solid white lines represent $2 \mathrm{~mm}$, and the black lines represent $200 \mu \mathrm{m}$. Ovule was marked with a white arrow.

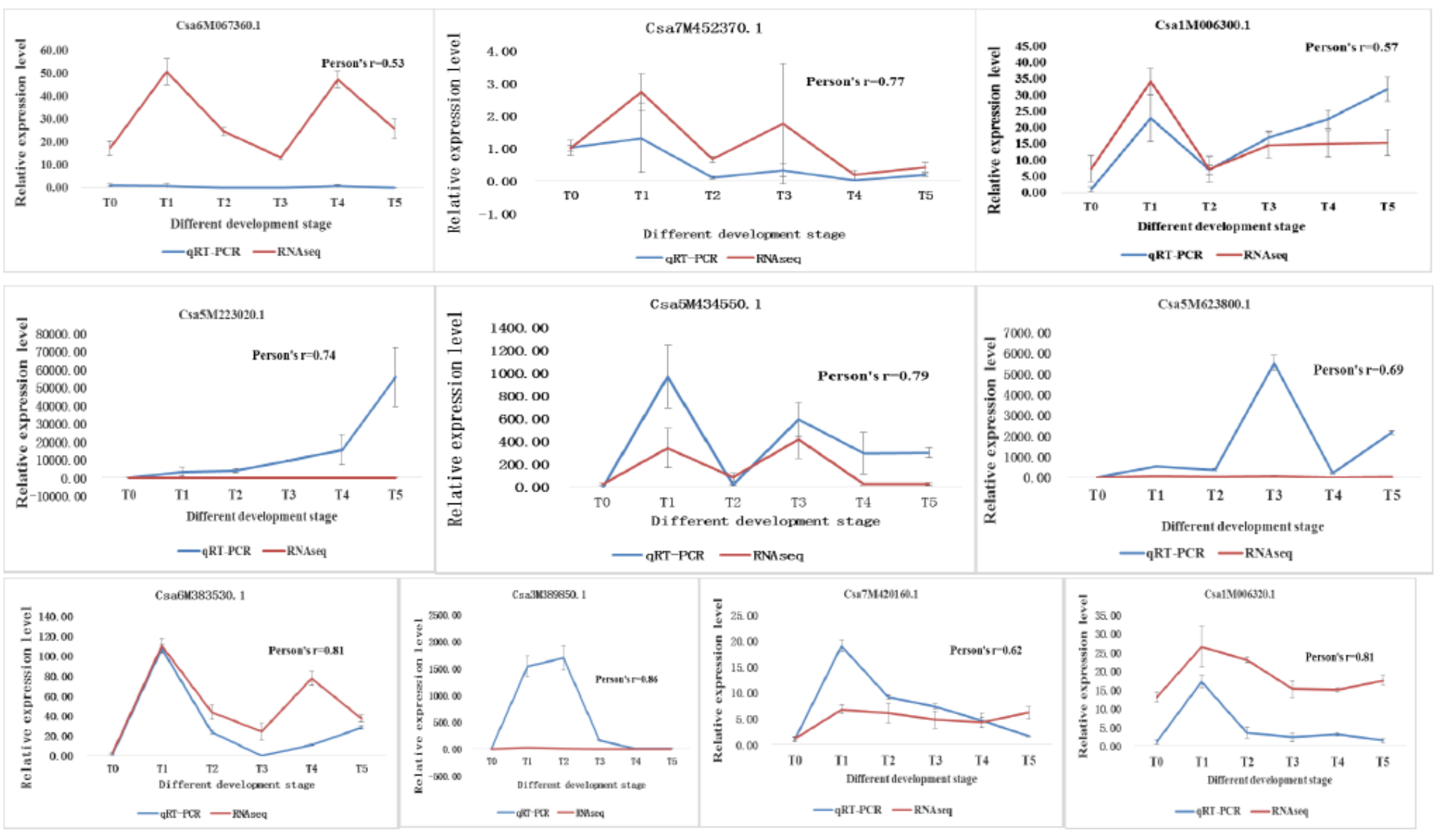

\section{Figure 2}

Validation of differentially expressed genes and correlation between RNA-seq and qRT-PCR qRT-PCR of 7 up-regulated genes involved in plant hormone signal transduction and 3 plant-pathogen interaction genes in whole ovary culture were analyzed. Close correlations (Person's $r=0.53,0.77,0.57,0.74,0.79,0.69,0.81$, $0.86,0.62,0.81$ ) were observed between relative expression levels in RNA-seq and qRT-PCR, validating the RNA-Seq methodology described here for quantitative analysis of the cucumber transcriptome. Three independent experimental replicates were analyzed for each sample, and data were showed as mean \pm SE $(n=3)$. 


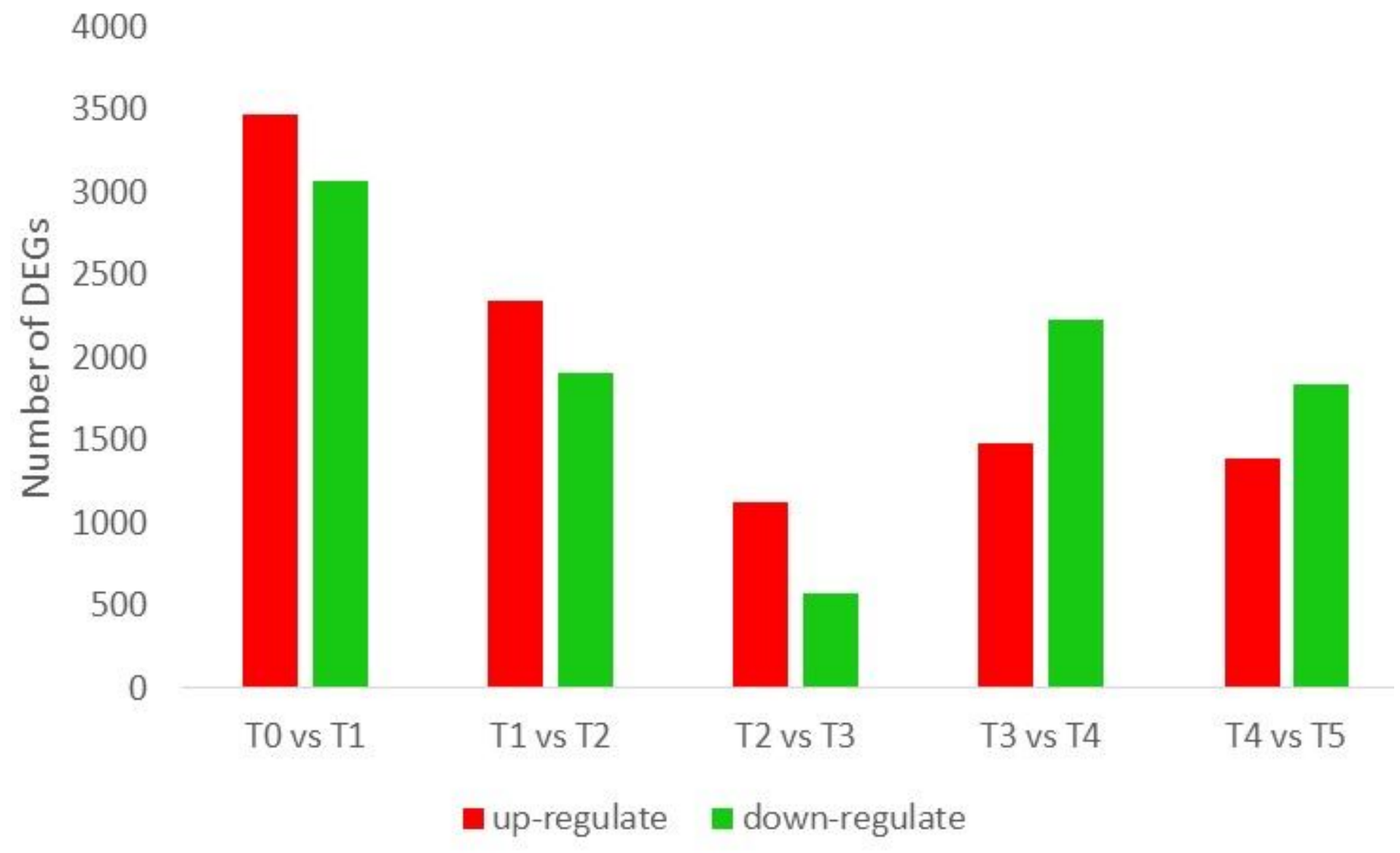

Figure 3

The total number of up-regulated and down-regulated genes Red color represents up-regulated, and green represents down-regulated 


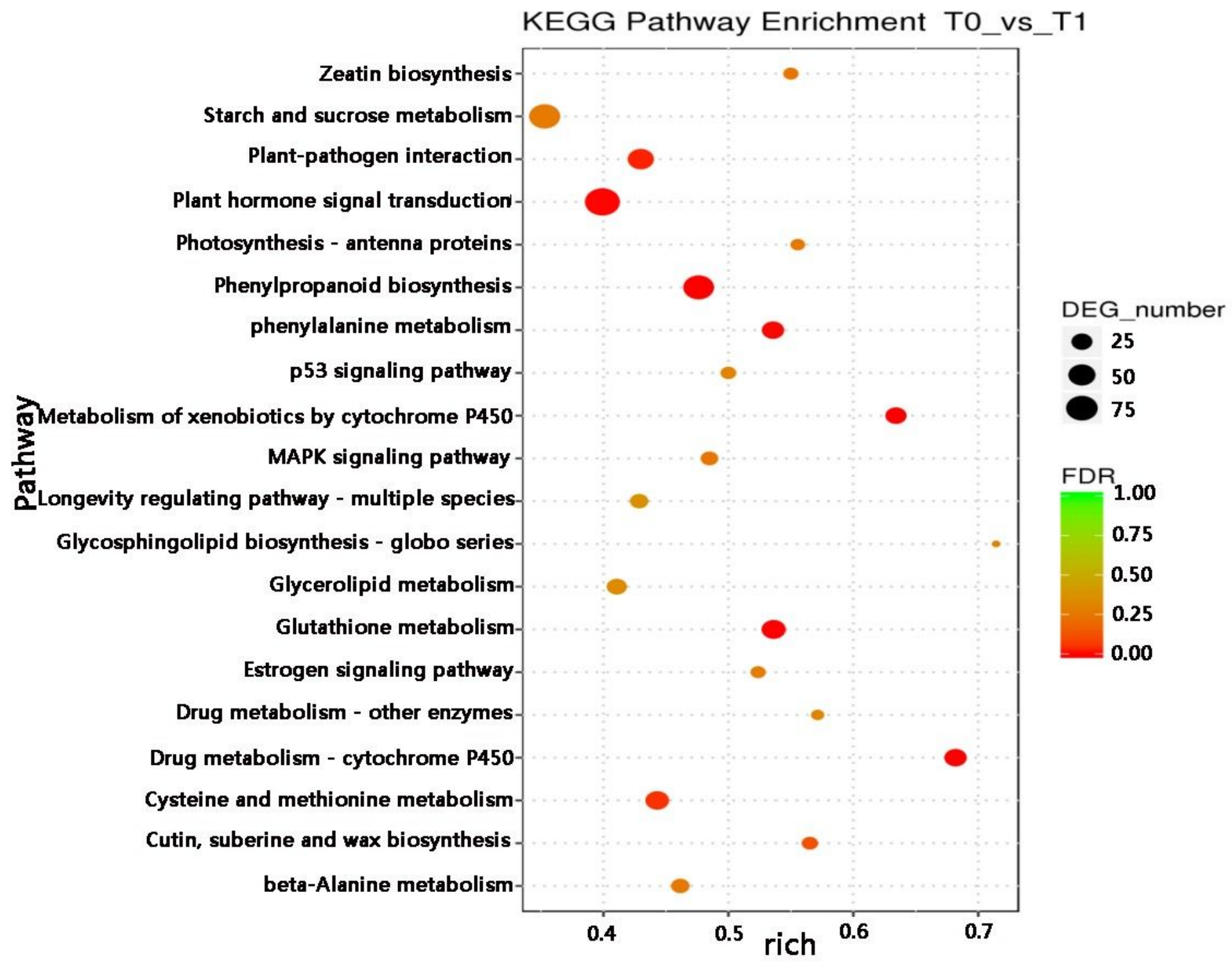

Figure 4

KEGG pathway enrichment analysis based on the differentially expressed genes in early embryo development The longitudinal coordinates was KEGG Pathway, and the abscissa was richfactor; the size of the dots in the graph represented the number of differentially expressed genes annotated to the path, and the color represented the significant $P$ value of the path. The 20 most significant paths were shown in the picture. 


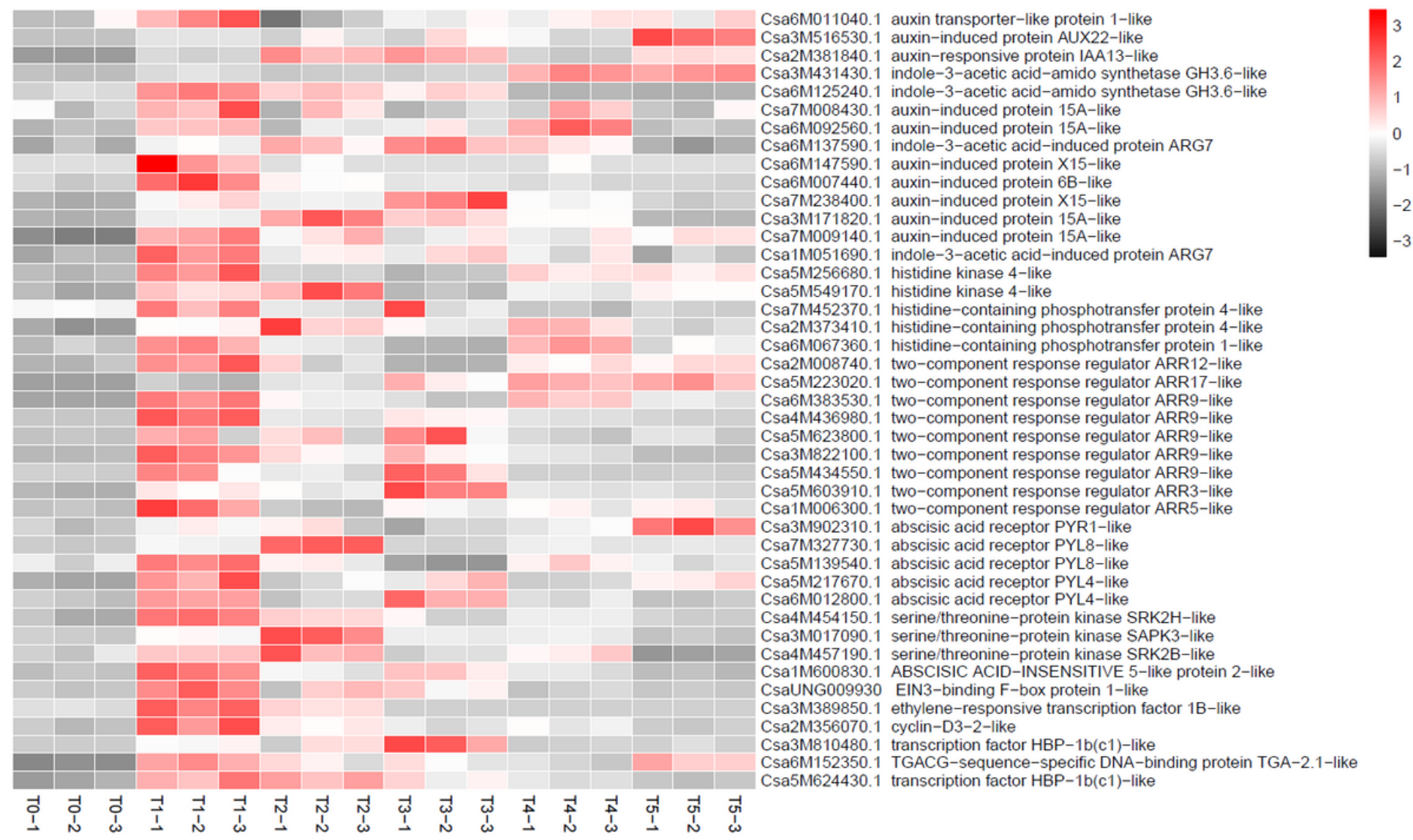

\section{Figure 5}

The matrix graph of up-regulated expression genes in the plant hormone signal transduction pathway in six time points The absolute values of the relative expression of up-regulated genes were indicated by the depth of color. The abscissa of the matrix graph showed the six time points. The vertical ordinate of the matrix graph showed the name of the up-regulated genes. The up-regulated genes were arrayed according to the hormonal signal transduction flows, which were classified into six groups: auxin, cytokinin, abscisic acid, ethylene, brassinosteroid, salicylic acid. 
T1_vs_T2

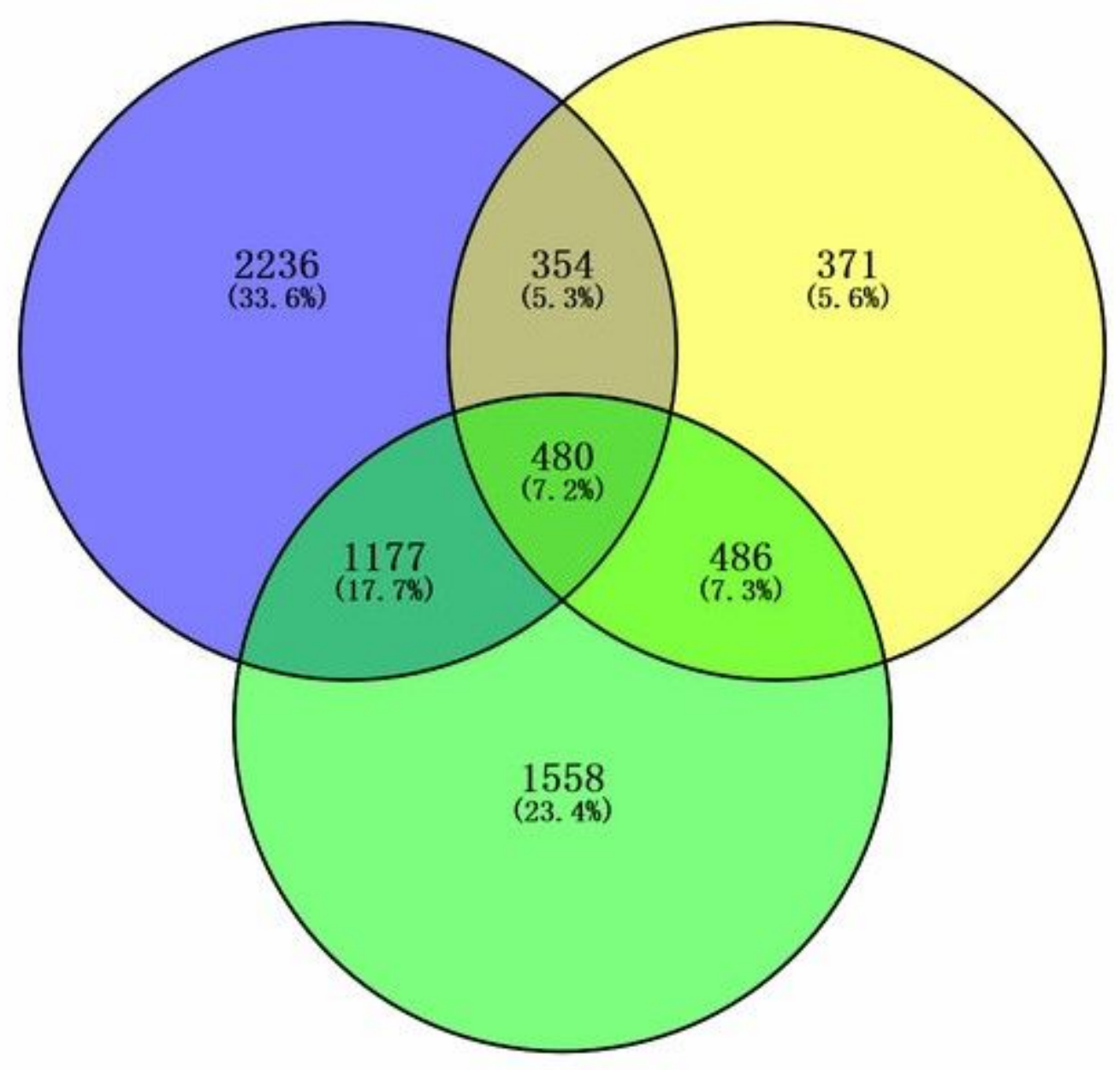

T3_vs_T4

Figure 6

Venn diagram showed differentially expressed genes in the stage from embryogenesis to the mature stage The DEG sets (T1 vs T2, T2 vs T3 and T3 vs T4) described in Fig. 3 were analyzed by using the Venn method. The numbers marked in the diagram indicated the number of continue express genes significantly expressed among the three DEGs sets. 


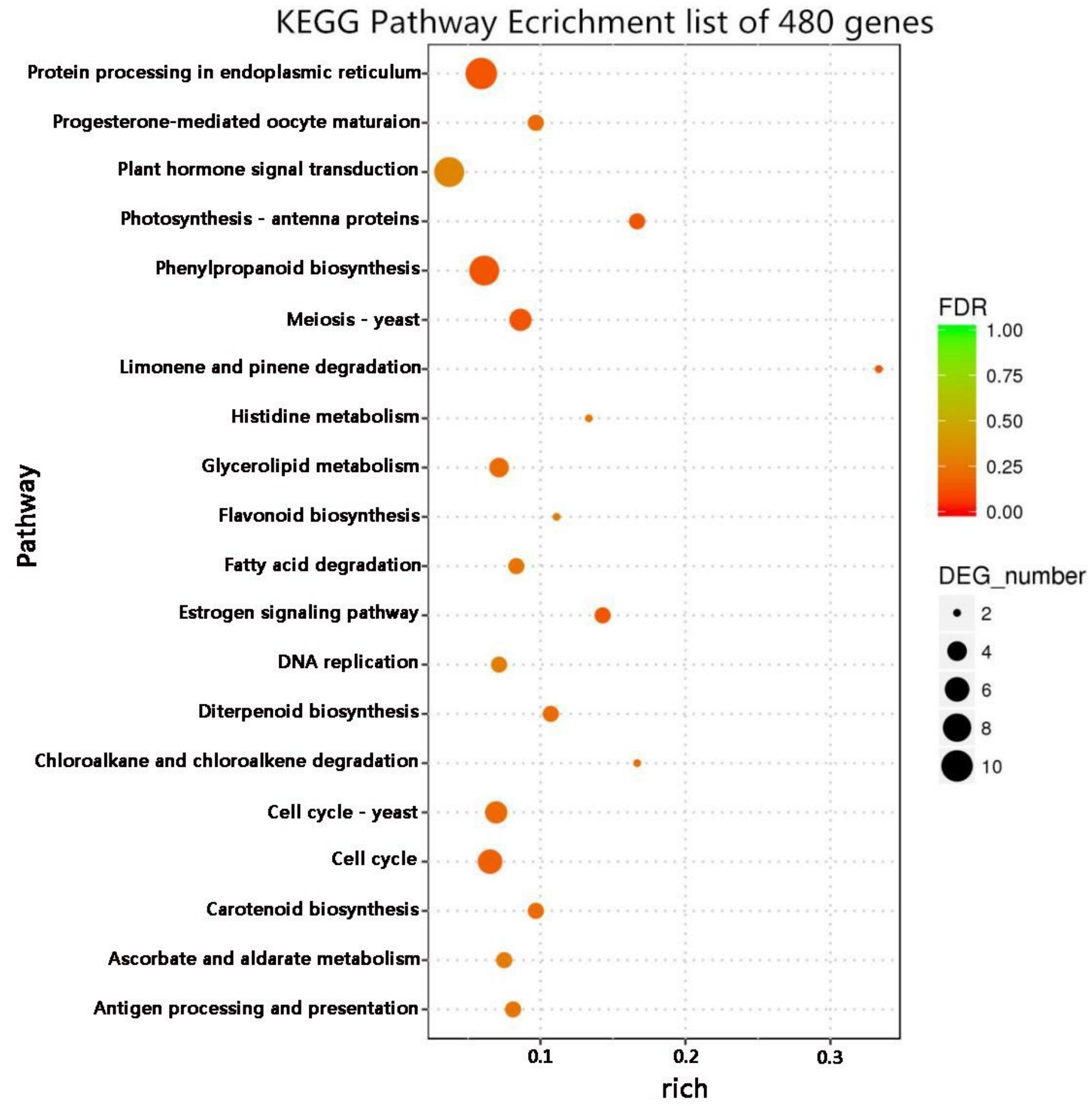

Figure 7

KEGG pathway enrichment analysis based on the differentially expressed genes from embryogenesis to the mature stage The longitudinal coordinates was KEGG pathway; the abscissa was rich factor; and the size of the dots in the graph represented the number of differentially expressed genes that were annotated to the path; the color represented the significant $P$ value of the path. The 20 most significant paths are shown in the picture. 


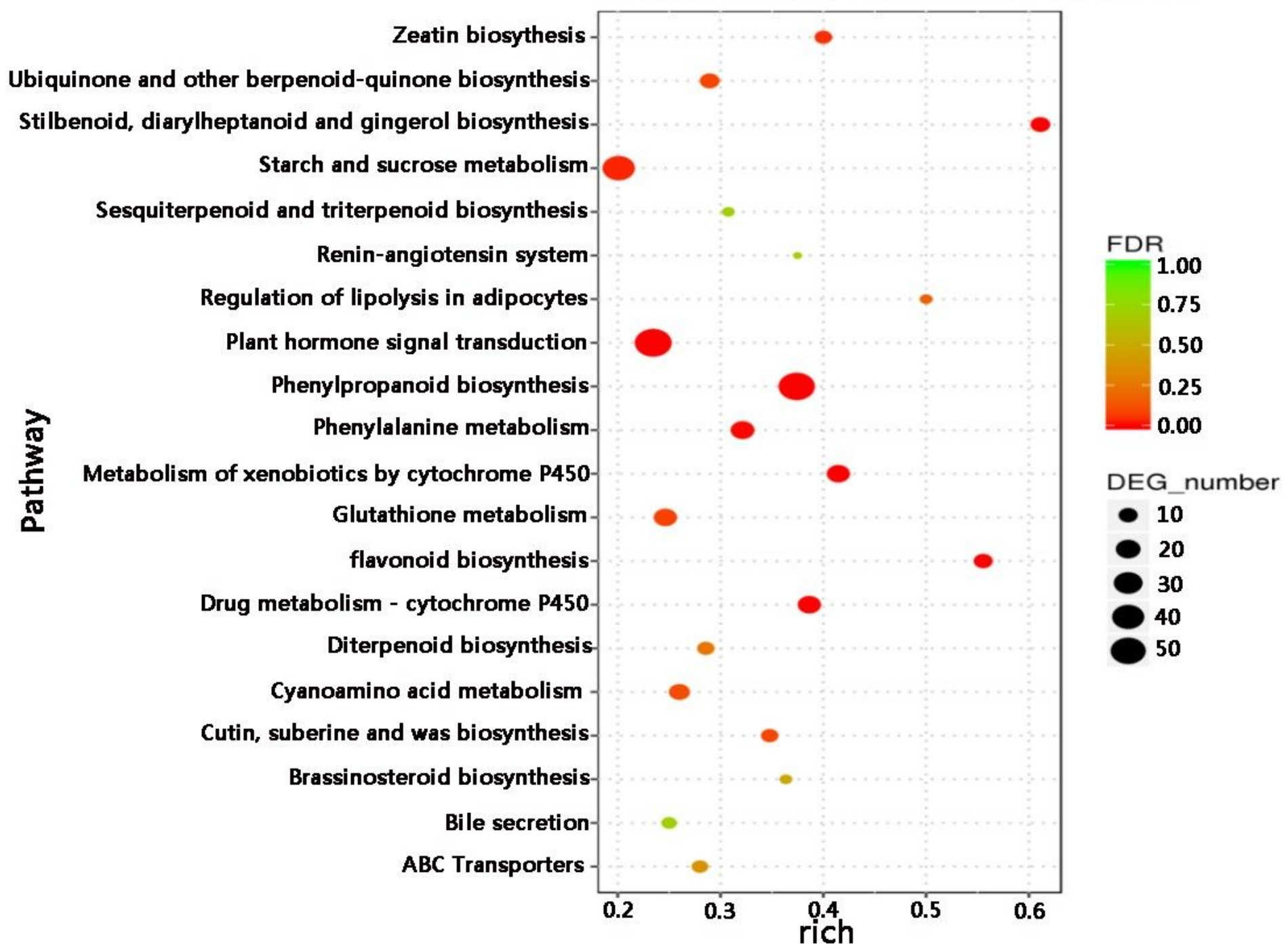

\section{Figure 8}

KEGG pathway enrichment analysis based on the differentially expressed genes at shoot formation stage The longitudinal coordinates was KEGG pathway; the abscissa was richfactor; the size of the dots in the graph represented the number of differentially expressed genes that were annotated to the path, and the color represented the significant $P$ value of the path. The 20 most significant paths were shown in the picture. 
Early embryo development Acquisition of embryogenic potential

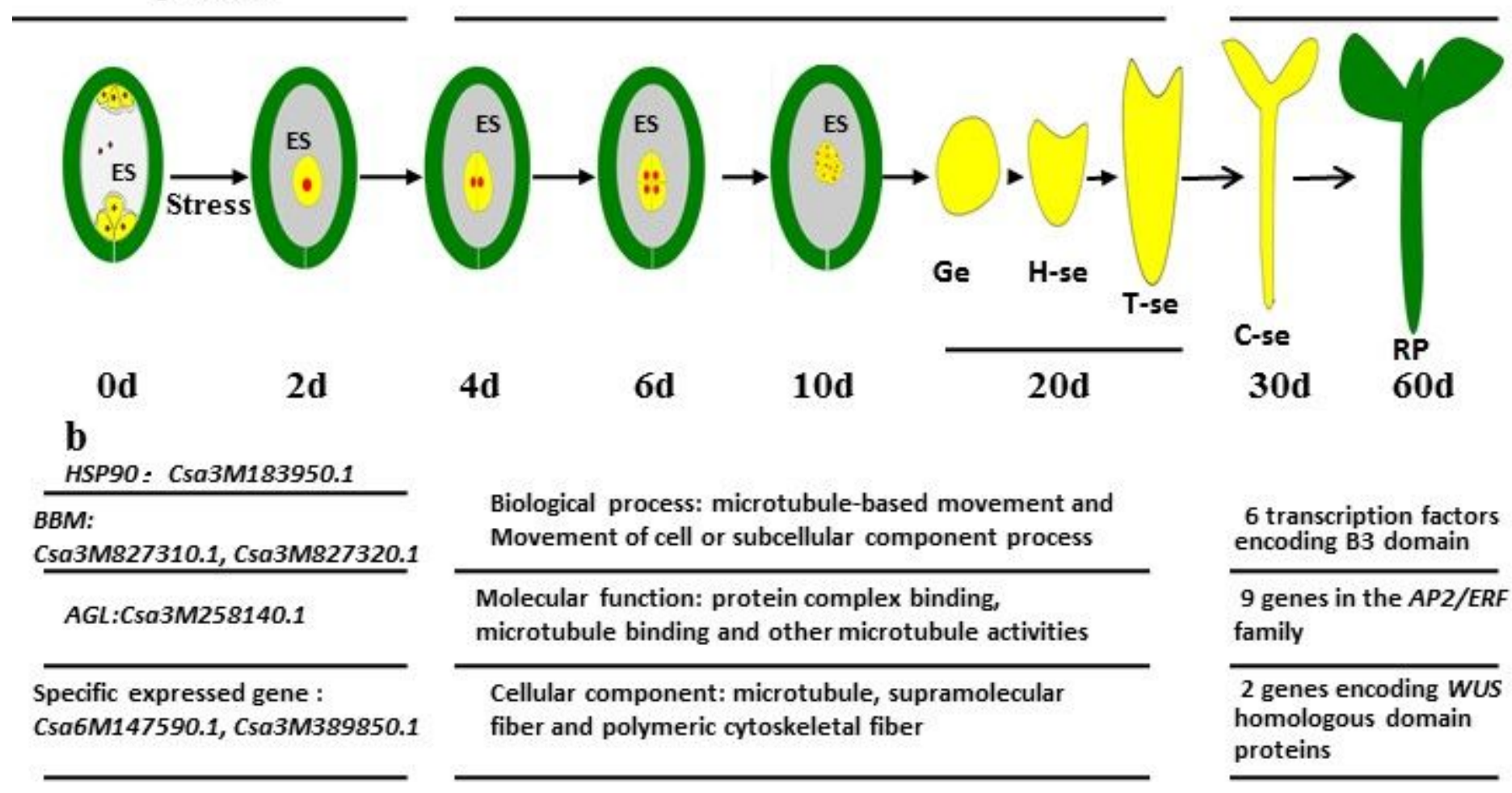

\section{Figure 9}

From cell division to cotyledon embryo formation
Shoot formation encoding B3 domain

9 genes in the AP2/ERF family

2 genes encoding WUS homologous domain proteins

Pattern diagram of embryogenesis and plant formation induced by cucumber ovary culture a embryogenesis and plant formation process; b molecular events at various stages; ES embryo sac; Ge globular embryo; $\mathrm{H}$-se heart-shaped embryo; T-se torpedo embryo; C-se cotyledon embryo; RP regenerated plant.

\section{Supplementary Files}

This is a list of supplementary files associated with this preprint. Click to download.

- supplement1.docx 